\title{
Stochastic Inventory System With Different Rates of Production
}

\author{
Mohammad Ataullah, Jahangirnagar University, Bangladesh \\ iD https://orcid.org/0000-0003-3778-7209
}

Mohammad Ekramol Islam, Department of Business Administration, Northern University Bangladesh

Md. Sharif Uddin, Jahangirnagar University, Bangladesh

\begin{abstract}
This article analyzes a solitary item stochastic inventory model with two distinctive generation rates where a request pursues Poisson distribution and an item has a limited lifetime which is level dependent. It is expected that the framework be on a foreordained level and the framework is changed over to ON mode from OFF mode with a noteworthy exchanging time with exponential parameter $\alpha$. During the switching time, no interest will be served, the interest during the exchange time is lost. Here, excesses are permitted and during accumulations, the production rate is higher than that of ordinary generation time. Some framework attributes are shown with time variety.
\end{abstract}

\section{KEYWORDS}

Stochastic Process, Poisson Distribution, Product Lifetime, Switching Time, Level Dependent, Production Rate

\section{INTRODUCTION}

Inventory control is one the most significant criteria for store network the executives. The investigation of the stock model incorporates item-weakening trademark. In a few existing models, it is expected that items have boundless rack time yet, all things considered, circumstances, a specific measure of rot or waste is experienced on the loaded things. Weakening of things in the stock framework happened because of quality of certain elements lime stockpiling, climate condition including the idea of the specific item under investigation, out of them some might be transitory though others can be put away for an uncertain period without being died. The crumbling is generally an element of the aggregate sum of stock available. Consequently, the need to examine the short-lived stock framework emerges.

The purpose of this paper is three folded: (1) to give a stochastic inventory model utilizing Markov process for makers and/ or suppliers who give benefit guarantee for their item for a settled time duration after the deal, (2) To decide about system characteristics with numerical illustrations and (3) To survey the effect of modify process on associations benefit margin. In section Background, Authors displayed some past related works. In section Mathematical Model, they build up stock models and understand it to get state likelihood vectors. Utilizing state likelihood vectors, numerical consequences of the proposed stock models are given in section Numerical Results. Authors talk about the genuine Application and affect-ability investigation of created models in section conclusion. 


\section{BACKGROUND}

Numerous analysts in the field have officially completed a broad research work by accepting a steady rate of rot and consistent interest yet utilize a deterministic methodology that does not mull over the vulnerability of interest. In the case of backlogging, the backlogged demands are satisfied immediately when the ordered items are materialized. However, in some real-life situations the backlogged demands may have to wait even after the stock is replenished. This type of inventory problems is called inventory with postponed demands. Authors of the article added uncertainty by including a new variable that reflects the probability of different scenarios. A comprehensive and detailed review of the vacation queueing model can be found in the survey by Doshi (1986) and the books by Tian and Zhang (2006), Servi and Finn (2002)were first to study the queueing system with working vacation and provide the analysis of WDM optical access network using multiple wavelengths. According to Donald Erlenkotter (1990), Ford Whitman Harris first presented the familiar economic order quantity (EOQ) model in a paper published in 1913. Even though Harris's original paper was disseminated widely, it apparently was unnoticed for many years before its rediscovery in 1988. During this period much confusion developed over the origin of the EOQ model. Nahmias (1982) provided a reference list of 77 periodicals and books dealing with the ordering policies for perishable inventories. For more recent works on the busy period analysis of M/G/1/K we refer to Lee (1984). Ghosh et al. (2012) studied an optimal inventory replenishment policy for a deteriorating time quadratic demand and time-dependent partial backlogging, which depends on the length of the waiting time for the next replenishment over a finite time horizon and variable replenishment cycle. Selvaraju et al. (2013) analyzed an queue for two different working vacation termination policies namely a multiple working vacation policy and a single working vacation policy. Closed form solution and various performance measures like mean queue length and mean waiting times are derived.

Blackburn, J. and Scudder, G. (2009) examined supply chain design strategies for a specific type of perishable product fresh produce using melons and sweet corn as examples. Melons and other types of produce reach their peak value at the time of harvest; product value deteriorates exponentially post-harvest until the product is cooled to dampen the deterioration. Using the product's marginal value of time (MVT), the rate at which the product loses value over time in the supply chain. Ruxian (2010) provided a comprehensive introduction about the deteriorating items inventory management research status, where they reviewed the recent studies from a different perspective. First, this paper proposes some key factors which should be considered in the deteriorating inventory studies; then, from the perspective of study scope. Kalpakam and Arivarignan (1993) analyzed a multi-item inventory model with unit renewal demands and immediate delivery of orders under a joint replenishment policy. Where they derived various operational characteristics, expression for the long run total expected cost rate. Ramesh and Praby (2016) examines a study on vacation bulk queuing model with setup time and server timeout. Arrivals come in batches according to a Poisson Process with batch size X, where $\mathrm{X}$ is a random variable. If the queue size is empty after a service completion and the server goes for vacation. If the server finds the system empty, then the server waits for fixed time $\mathrm{c}$. At the expiration of this time, the server commences another vacation if no customer has arrived. Analytical results are derived for the mean waiting time in the system.

A major breakthrough in computation of transient probabilities for $M / G / 1$ is by approximating general service by Coxian-phase type distribution by Cox (1955). Approximation by phase type distribution leads to Markovian set up for analysis. Paul Manuel et al. (2007) dealt an inventory system in which the positive and negative demands occur according to independent Markovian arrival processes and lead time of the reorder, life time of the items, interval time between two successive selections from the pool and the reneging time points of the customers in the pool are independent and exponentially distributed. In the all the above models, the authors assumed that the pool size is finite and the pooled customers are selected only when the replenished inventory is above the replenishment point. Federgruen el al. (1998) considered a continuous review multi-item inventory system with 
compound Poisson demand processes; excess demands are backlogged and each replenishment requires a lead time. Berman and Kim (1999) assuming instantaneous order replenishments, they show that under both the expected discounted cost and the average cost per unit time criteria, the optimal policy is patient, that is, never to order when the system is empty, to place an order only when the inventory level drops to zero, and a threshold ordering policy is optimal. Laxmi and Jyothsna (2015) study a renewal input multiple vacations queuing model with balking, reneging and heterogeneous servers. They use supplementary variable and recursive techniques to obtain the steady-state probabilities of the model. Ayyappan and Shyamala (2013) obtained the time dependent solution and the corresponding steady state solutions and they also derived the performance measures, the mean queue size and the average waiting time explicitly.

Zeinab et al. (2012) developed an inventory model for a main class of deteriorating items, under stochastic lead time assumption, and considered a non-linear holding cost. Chan et al. (2006) solved transient solution of Markovian queuing networks considering boundary value method (BVMs). By applying algebraic multigrial (AMG) methods with modified restriction operator they solved the resulting system of linear equations. Feng-Tsung Cheng et al. (2010) investigates the optimal inventory replenishment policy for an economic production quantity (EPQ) model with backordering, rework and machine breakdown taking place in stock piling time.

Pearn and chang (2004) studied optimal management problem of the N-policy M/Ek/1 queuing system with removable service station under steady state condition. Berg et al. (1994) noticed that in the production-inventory systems a number of producing machines are susceptible to failure following which must be repaired to make them operative again. The machines' production can also be stopped deliberately due to stocking capacity limitations or any other relevant considerations. The interplay between the processes involved, namely, production, demand, and failure/repair or reliability, in conjunction with the shutdown policy used; determine the inventory accumulation process and possible shortages. Islam et al. (2013) presented an inventory system with postponed demands considering reneging pools and rejecting Buffer's customers. Giri and Dohi (2005) presented an exact formulation of stochastic EMQ model for an unreliable production system under a general framework in which the time to machine failure, corrective (emergency) and preventive (regular) repair times are assumed to be random variables. For exact financial implications of the lot-sizing decisions, the EMQ model is formulated based on the net present value (NPV) approach. Then, by taking limitation on the discount rate, the traditional long-run average cost model is obtained. Significant part of this work of Islam et al. (2007) where they presented a perishable stochastic inventory system with different rates of production and random switching time.

\section{MATHEMATICAL MODELS}

\section{Assumptions and Notations}

Assumptions

1. Initially inventory level is at order level

2. Demand follow Poisson process

3. In the production system, two production rates are considered and production rate is higher during backlogs than normal time

4. When inventory level reaches at a predetermine level at $-\mathrm{N}$, the system converted to $\mathrm{ON}$ mode from OFF mode with a parameter which follows exponential distribution.

5. Items perishability is level dependent.

6. During switching time, i.e. Time needs from off mode to On mode, no demand is allowed, so demand at the switching time is lost forever.

7. If inventory level reaches at order level, production process will be switched off. 
Notations

i. $\quad \lambda \rightarrow$ Arrival rate

ii. $\quad \mu \rightarrow$ Production rate during backlogs

iii. $\delta \rightarrow$ Normal production rate

iv. $\mathrm{S} \rightarrow$ Order level

v. $\quad \rho \rightarrow$ The decay rate of items

vi. $\quad \alpha \rightarrow$ Switching time

vii. $I(t)$ Inventory level at time $\mathrm{t}$

viii. $E \rightarrow E_{1} \cup E_{2}$ is the state space of the process

where, $E_{1}=\{(t, 0): t=-N+1, \ldots, S\}$ and

$E_{2}=\{(t, 1): t=-N+1, \ldots, S-1\}$

\section{Case-I: When Items are Perishable and $\boldsymbol{A}$ is the Decay Rate:}

In this case, Authors assume that the inventory level is $S$ at the starting point and the system is in OFF mode. Demand follows Poisson distribution with rate $\lambda$. Inventory level will be depleted due to customers and items will decay with time passes, which is level dependent. When inventory level reaches to the level $-\mathrm{N}$ then the system will be switched $\mathrm{ON}$ mode. In the inventory system, inventory level $I(t)$ takes the value

$$
A=\{-N,-N+1, \ldots, 0,1,2, \ldots, S\}
$$

To get a two-dimensional Markov process, we introduce the $\{X(t), t \geq 0\}$ Where, $X(t)$ is defined by $X(t)= \begin{cases}1 & \text { when production is } \mathrm{ON} \\ 0 & \text { when production is } \mathrm{OFF}\end{cases}$

Now, the infinitesimal generator of the two-dimensional Markov process $\{I(t), X(t) ; t \geq 0\}$ is defined on the state space $\mathrm{E}$. it is noted that the Markov process is a pure birth and death process during the transition from the state $(S, 0)$ through the state $(S-1,0), \ldots,(-N+1,0)$ when the production process is in OFF mode. When inventory level in the state $(-N, 0)$ then the system is switched ON. Switching time follows exponential distribution with parameter $\alpha$ and reached the state $(N, 1)$ from $(-N, 0)$. From this state onward, the process will ON until it reaches the level $(S, 0)$.

Let us assume $I(0)=S$ and $X(0)=0$. Let us consider the transition probabilities:

$$
P_{(S, 0)(i, j)}(t)=P\{I(t), X(t)=(i, j) \mid I(0), X(0)=(S, 0)\}
$$


From now onwards we can write

$P_{(i, j)}(t)$ for $P_{(S, 0)(i, j)}(t)$

Kolmogorov difference differential equations for the system $P_{(i, j)}(t)$ are given bellow:

When system is OFF mode:

$$
\begin{aligned}
& P_{(S, 0)}^{\prime}(t)=-(\lambda+S \rho) P_{(S, 0)}(t)+\delta P_{(S-1,1)}(t) \\
& P_{(i, 0)}^{\prime}(t)=-(\lambda+i \rho) P_{(i, 0)}(t)+(\lambda+(i+1) \rho) P_{(i+1,0)}(t) ; i=S-1, \ldots, 0 \\
& P_{(i, 0)}^{\prime}(t)=-\lambda P_{(i, 0)}(t)+\lambda P_{(i+1,0)}(t) ; i=-1, \ldots,-N+1 \\
& P_{(-N, 0)}^{\prime}(t)=-\alpha P_{(-N, 0)}(t)+\lambda P_{(-N+1,0)}(t)
\end{aligned}
$$

When the system is ON mode:

$$
\begin{aligned}
& P_{(S-1,1)}^{\prime}(t)=-(\lambda+i \rho+\delta) P_{(S-1,1)}(t)+(\lambda+i \rho) P_{(S, 0)}(t) \\
& P_{(i, 1)}^{\prime}(t)=-(\lambda+i \rho+\delta) P_{(i, 1)}(t)+(\lambda+(i+1) \rho) P_{(i+1,0)}(t)+\delta P_{(i+1,1)}(t) ; i=\mathrm{S}-2, \ldots, 0 \ldots \\
& P_{(i, 1)}^{\prime}(t)=-(\lambda+\mu) P_{(i, 1)}(t)+\lambda P_{(i+1,1)}(t)+\mu P_{(i+1,1)}(t) ; i=-\mathrm{N}+1, \ldots,-2,-1 \\
& P_{(-N, 1)}^{\prime}(t)=-\mu P_{(-N, 1)}(t)+\alpha P_{(-N, 0)}(t)+\lambda P_{(-N+1,1)}(t)
\end{aligned}
$$

Writer of the article solve this system of ordinary differential equations by using the RungeKutta method of fourth order based on arbitrary parameters and plot the performance measures based on ODE's. The effect of various parameters on the system performance measures such as expected inventory level; expected number of customers in the system and mean waiting time in the system are studied. They use MATLAB R2016a software to compute the system characteristics. 


\section{System Characteristics for Case- I:}

1. Mean inventory level in the system

Let the expected inventory level

$$
L s(t)=\sum_{i=1}^{S} i P_{(i, 0)}(t)+\sum_{i=1}^{S-1} i P_{(i, 1)}(t)
$$

2. Expected number of perishable items

Let the number of perishable items

$$
L p(t)=\sum_{i=1}^{S} i \rho P_{(i, 0)}(t)+\sum_{i=1}^{S-1} i \rho P_{(i, 1)}(t)
$$

3. Expected backlogs in the system

Let the expected backlogs

$$
L b(t)=\sum_{i=-N}^{-1}|i| P_{(i, 0)}(t)+\sum_{i=-N}^{-1}|i| P_{(i, 1)}(t)
$$

4. Expected number of customers lost

Let expected number of customers lost $C L(t)=\lambda P_{(-N, o)}(t)+\lambda P_{(-N, 1)}(t)+\alpha \lambda P_{(-N, 0)}(t)$

5. Expected total cost of the system

$$
E T C(t))=L+c_{1} L s(t)+c_{2} L p(t)+c_{3} L b(t)+c_{4} C L(t)
$$

\section{Numerical Results and Discussions for Case- I}

In all numerical computations, parameters are taken as

$$
\begin{aligned}
& S=3, N=2, \lambda=1, \alpha=0.21, \rho=0.1, \mu=3, \delta=2, \mathrm{~N}=2, \mathrm{~L}=25, \\
& c_{1}=0.15, c_{2}=0.25, c_{3}=0.1, c_{4}=0.35 .
\end{aligned}
$$


Figure 1. Mean inventory level vs Time

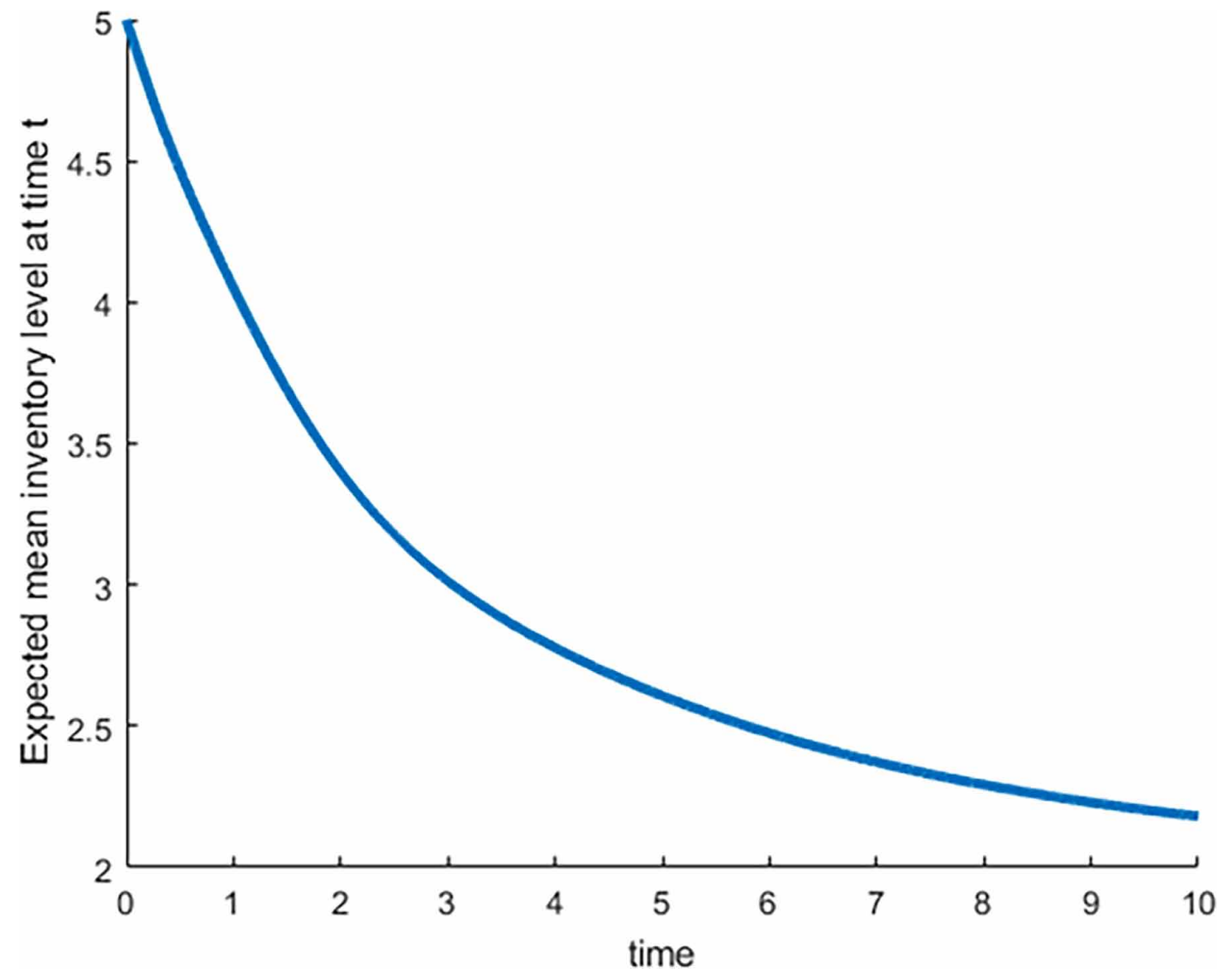

Numerical outcomes have been gotten by applying Runge-kutta fourth request technique in the arrangement of standard differential conditions (I) through viii) with the assistance of computational programming MATLAB R2016a for the parametric qualities steady with time interim $0 \leq t \leq 10$ as appeared in the diagrams. Diagrams of different parameters versus time have been demonstrated Figures 1-5 for case-I. Figure 1 investigates that the stock dimension diminished with time yet for long time interim, it is decrease rate lower than from beginning stage. Figure 2 demonstrates that the quantity of transient things raises quickly from starting and after some time passing diminishes perishability rate. Figure 3 Explain the quantity of overabundances with time variety. The figure demonstrates that average number of clients in the framework increment at the beginning stage however after some time, as creation rate is higher amid excesses period than that of ordinary generation day and age for higher estimation of generation rate gives lesser number of clients in the framework, which is very sensible. From Figure 4 we see that the rate of lost deal is nearly low, which is reason by the way that underlying likelihood has been lessened essentially because of which some the probabilities have their qualities zero after some time which implies that probabilities are not relying on time just but rather upon different parameters as well. Figure 5 exhibits the normal aggregate expense of the framework, which demonstrate that at first aggregate expense, is higher than whatever remains of era considered in Case-I. 
Figure 2. Expected backlogs vs Time

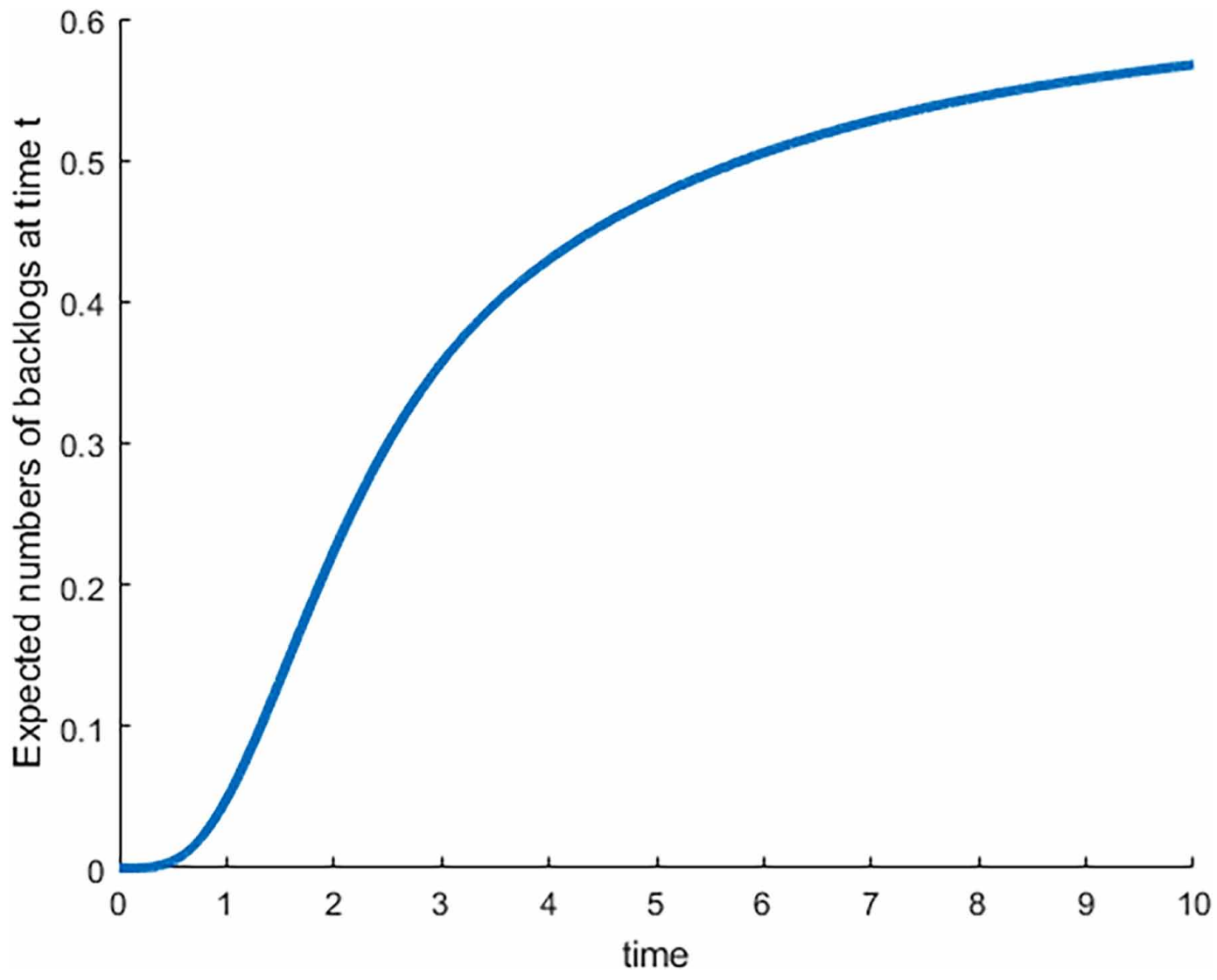

\section{Case-II: When Items are Non-Perishable:}

In this case, Authors do not consider items deterioration rete, that is $\rho=0$ and Kolmogorov difference differential equations for the system $P_{(i, j)}(t)$ are given bellow:

When system is OFF mode:

$$
\begin{aligned}
& P_{(s, 0)}^{\prime}(t)=-(\lambda+S) P_{(s, 0)}(t)+\delta P_{(S-1,1)}(t) \\
& P_{(i, 0)}^{\prime}(t)=-(\lambda+i) P_{(i, 0)}(t)+(\lambda) P_{(i+1,0)}(t) ; i=S-1, \ldots, 0 \\
& P_{(i, 0)}^{\prime}(t)=-\lambda P_{(i, 0)}(t)+\lambda P_{(i+1,0)}(t) ; i=-1, \ldots,-N+1
\end{aligned}
$$


Figure 3. Expected perishable items vs Time

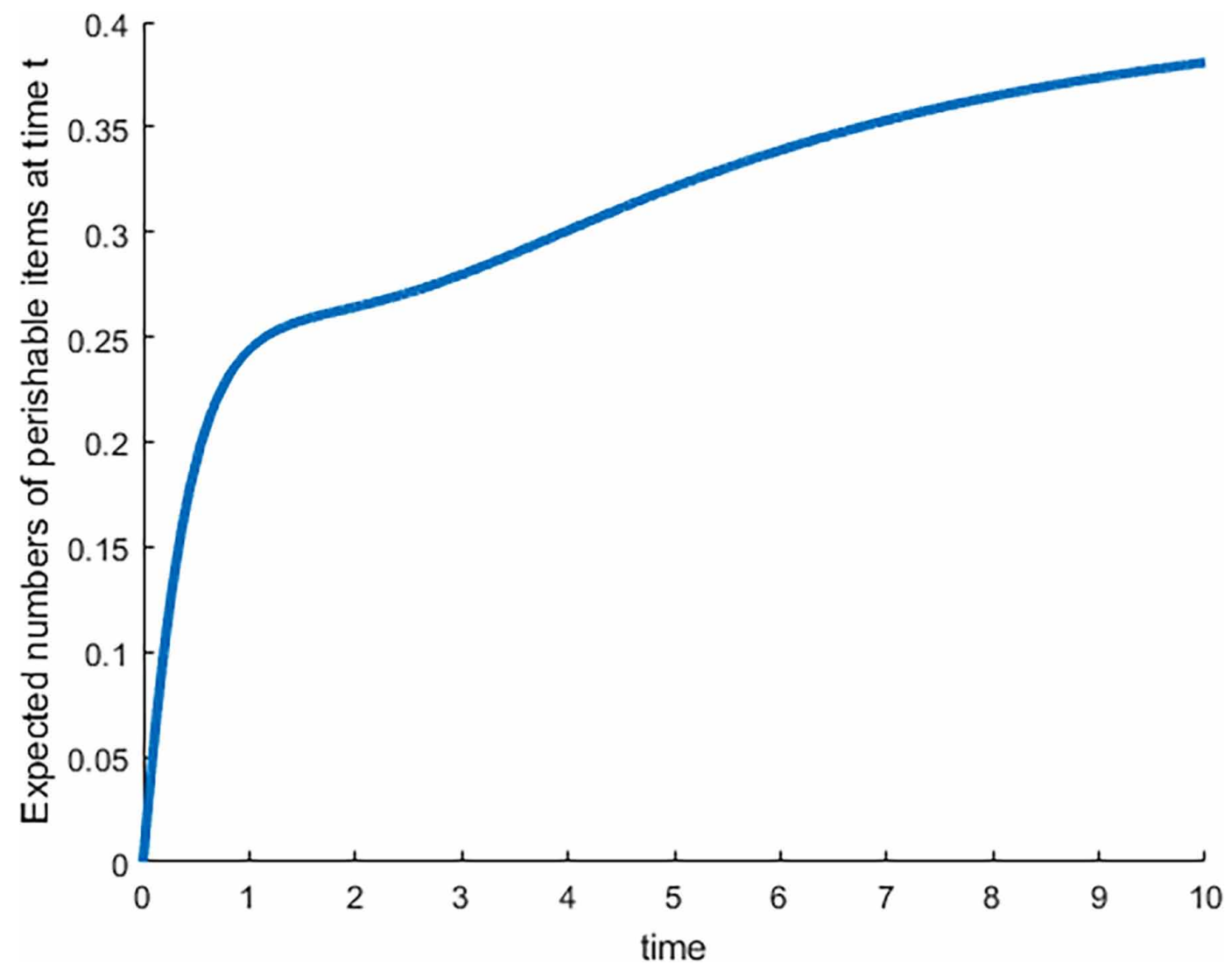

$P_{(-N, 0)}^{\prime}(t)=-\alpha P_{(-N, 0)}(t)+\lambda P_{(-N+1,0)}(t)$

When the system is ON mode:

$$
\begin{aligned}
& P_{(S-1,1)}^{\prime}(t)=-(\lambda+\delta) P_{(S-1,1)}(t)+(\lambda) P_{(S, 0)}(t) \\
& P_{(i, 1)}^{\prime}(t)=-(\lambda+\delta) P_{(i, 1)}(t)+(\lambda) P_{(i+1,0)}(t)+\delta P_{(i+1,1)}(t) ; i=\mathrm{S}-2, \ldots, 0 \\
& P_{(i, 1)}^{\prime}(t)=-(\lambda+\mu) P_{(i, 1)}(t)+(\lambda+\mu) P_{(i+1,1)}(t) ; i=-\mathrm{N}+1, \ldots,-2,-1 \\
& P_{(-N, 1)}^{\prime}(t)=-\mu P_{(-N, 1)}(t)+\alpha P_{(-N, 0)}(t)+\lambda P_{(-N+1,1)}(t)
\end{aligned}
$$


Figure 4. Expected lost sale vs Time

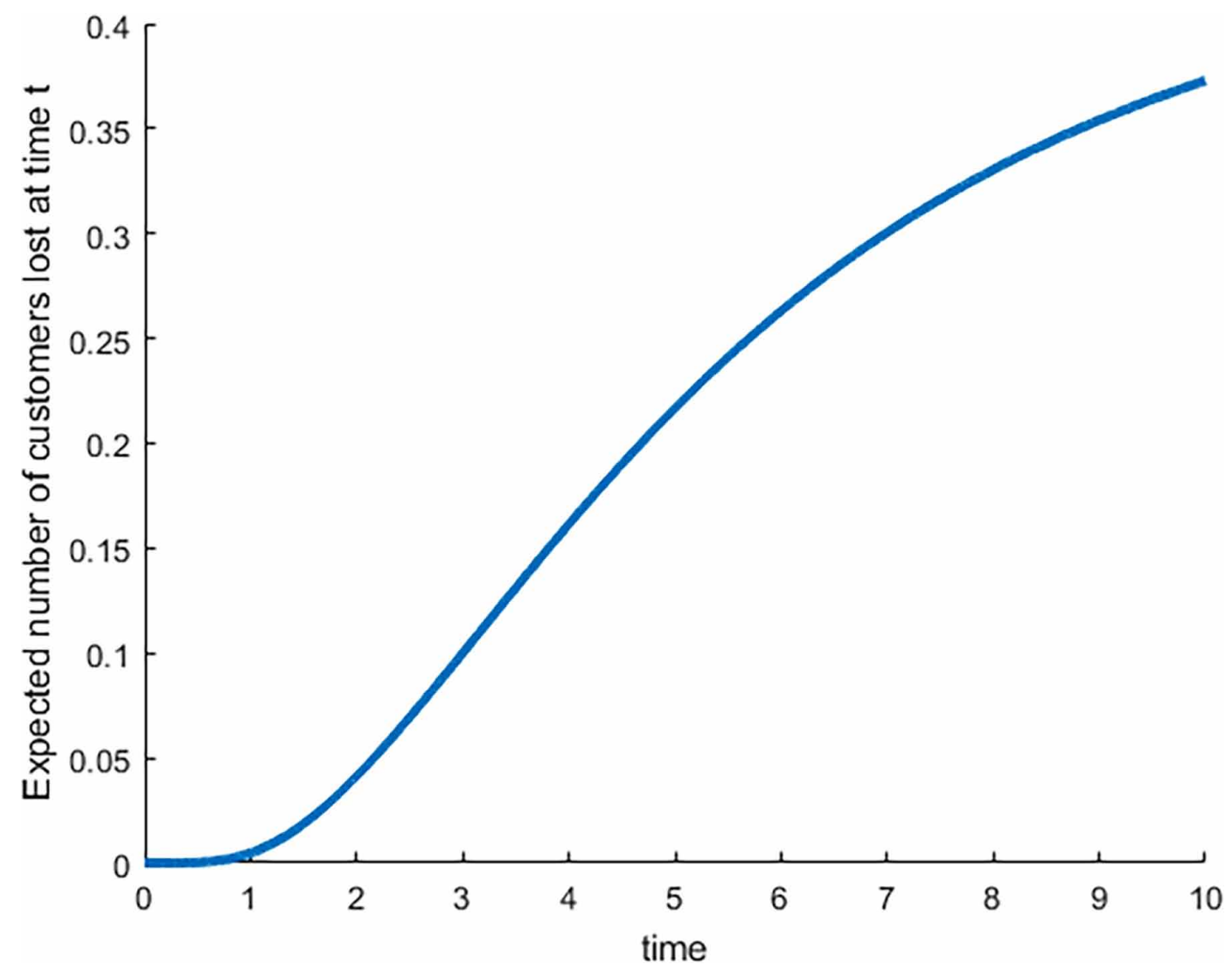

\section{Performance Measures for Case- II}

Mean Inventory Level in the System

Let the expected inventory level

$$
L s(t)=\sum_{i=1}^{S} i P_{(i, 0)}(t)+\sum_{i=1}^{S-1} i P_{(i, 1)}(t)
$$

\section{Expected Number of Perishable Items}

Let the number of perishable items

$$
L p(t)=\sum_{i=1}^{S} i P_{(i, 0)}(t)+\sum_{i=1}^{S-1} i P_{(i, 1)}(t)
$$

\section{Expected Backlogs in the System}

Let the expected backlogs 
Figure 5. Expected total cost vs Time

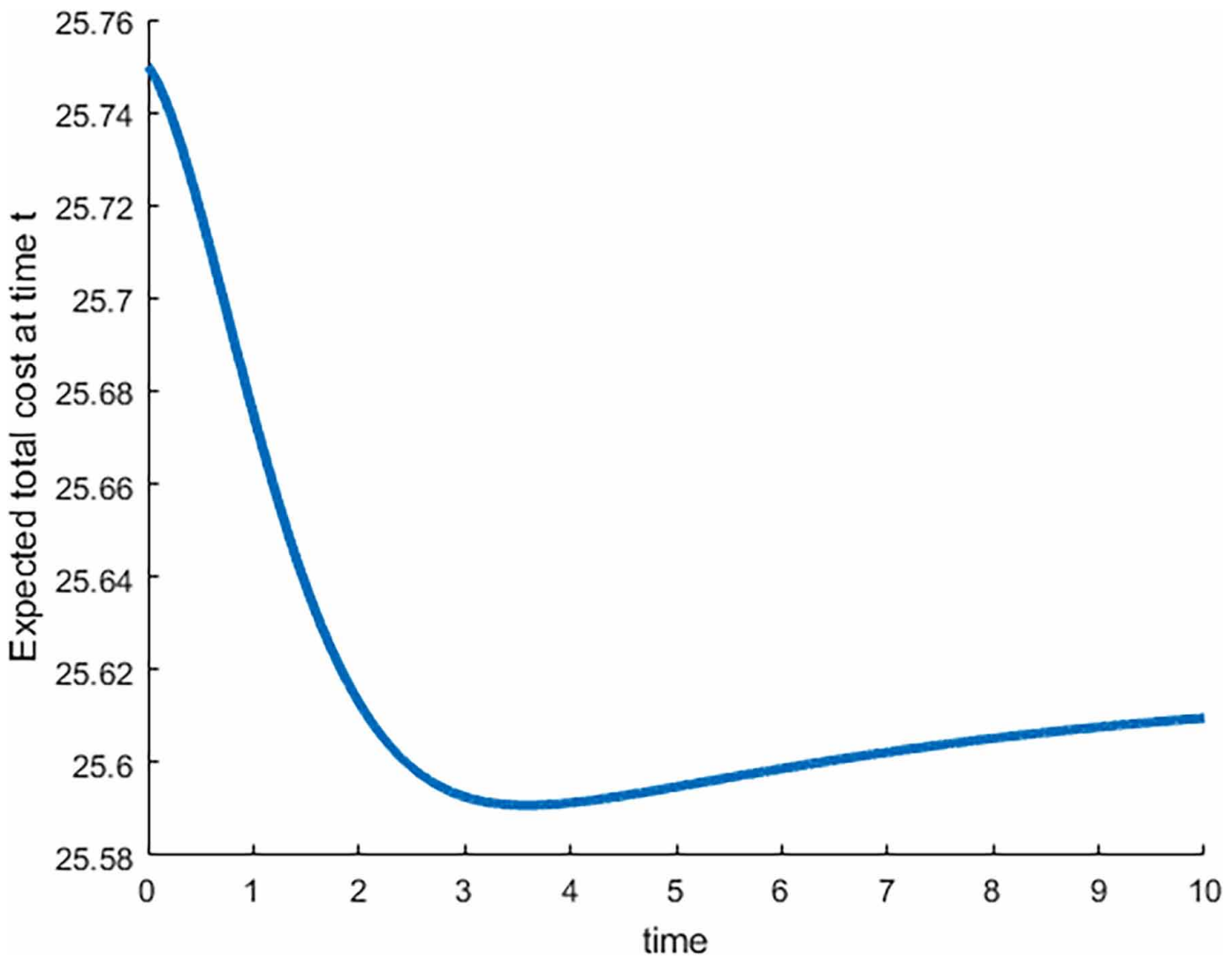

$L b(t)=\sum_{i=-N}^{-1}|i| P_{(i, 0)}(t)+\sum_{i=-N}^{-1}|i| P_{(i, 1)}(t)$

\section{Expected Number of Customers Lost}

Let expected number of customers lost $C L(t)=\lambda P_{(-N, o)}(t)+\lambda P_{(-N, 1)}(t)+\tau \lambda P_{(-N, 0)}(t)$

Expected Total Cost of the System

$\operatorname{ETC}(t))=L+c_{1} L s(t)+c_{2} L p(t)+c_{3} L b(t)+c_{4} C L(t)$.

Numerical Results and Discussions for Case- II

In all numerical computations, parameters are taken as

$S=3, N=2, \lambda=1, \alpha=0.21, \mu=3, \delta=2, \mathrm{~L}=25, c_{1}=0.15, c_{2}=0.25, c_{3}=0.1, c_{4}=0.35$. 
Numerical outcomes have been gotten by applying Runge-kutta fourth request technique in the arrangement of standard differential conditions (I) through viii) with the assistance of computational programming MATLAB R2016a for the parametric qualities steady with time interim $0 \leq t \leq 10$ as appeared in the diagrams. Diagrams of different parameters versus time have been demonstrated Figures 6-9 for Case-II. Figure 6 investigates that the stock raised quickly for short time but for long time interim it decrease at lower rate. From Figure 7, we see that the rate of lost deal is very high at the beginning time after some time, which decreases, as the production rate is higher than the normal production period. Figure 8 demonstrates the average number of backlogs increment at the beginning stage however after some time, at a certain rate it decreases in the end. Figure 9 exhibits the normal aggregate expense of the framework, which demonstrate that at first aggregate expense, is higher than whatever remains of era considered in Case-II.

\section{CONCLUSION}

Investigation of single item inventory model under time subordinate entry and administration rates has been made. Under the examination the numerical outcomes for different execution measures have been acquired by utilizing Runge-kutta fourth order method with MATLAB R2016a. The model is studied for both perishable and non-perishable items and it can be considered under various servers' arrangement, which may give progressively broad arrangement under time subordinate circumstances in order to make the model increasingly reasonable.

Figure 6. Mean inventory level vs time

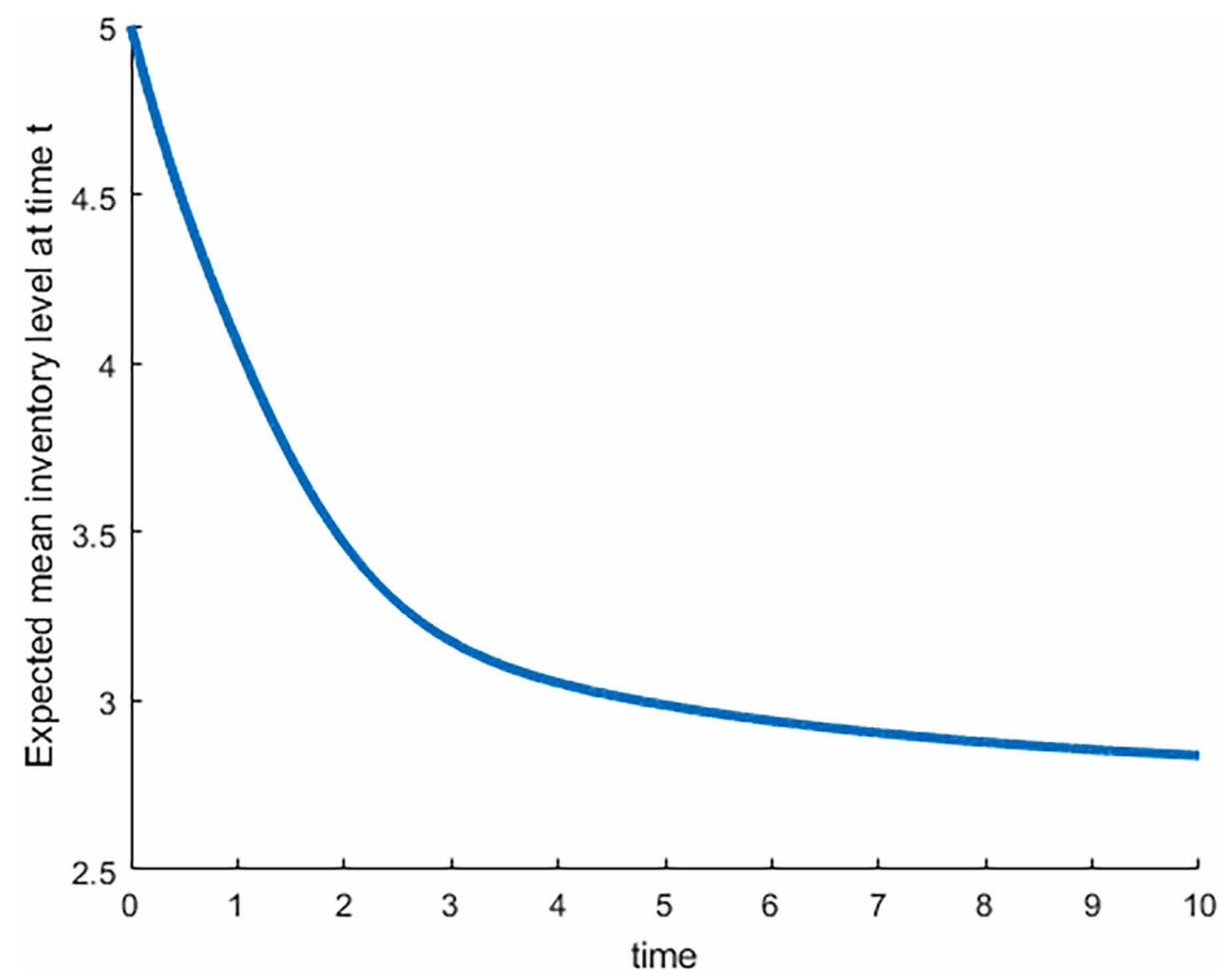


International Journal of Operations Research and Information Systems

Volume 11 • Issue 2 • April-June 2020

Figure 7. Expected numbers of backlogs vs time

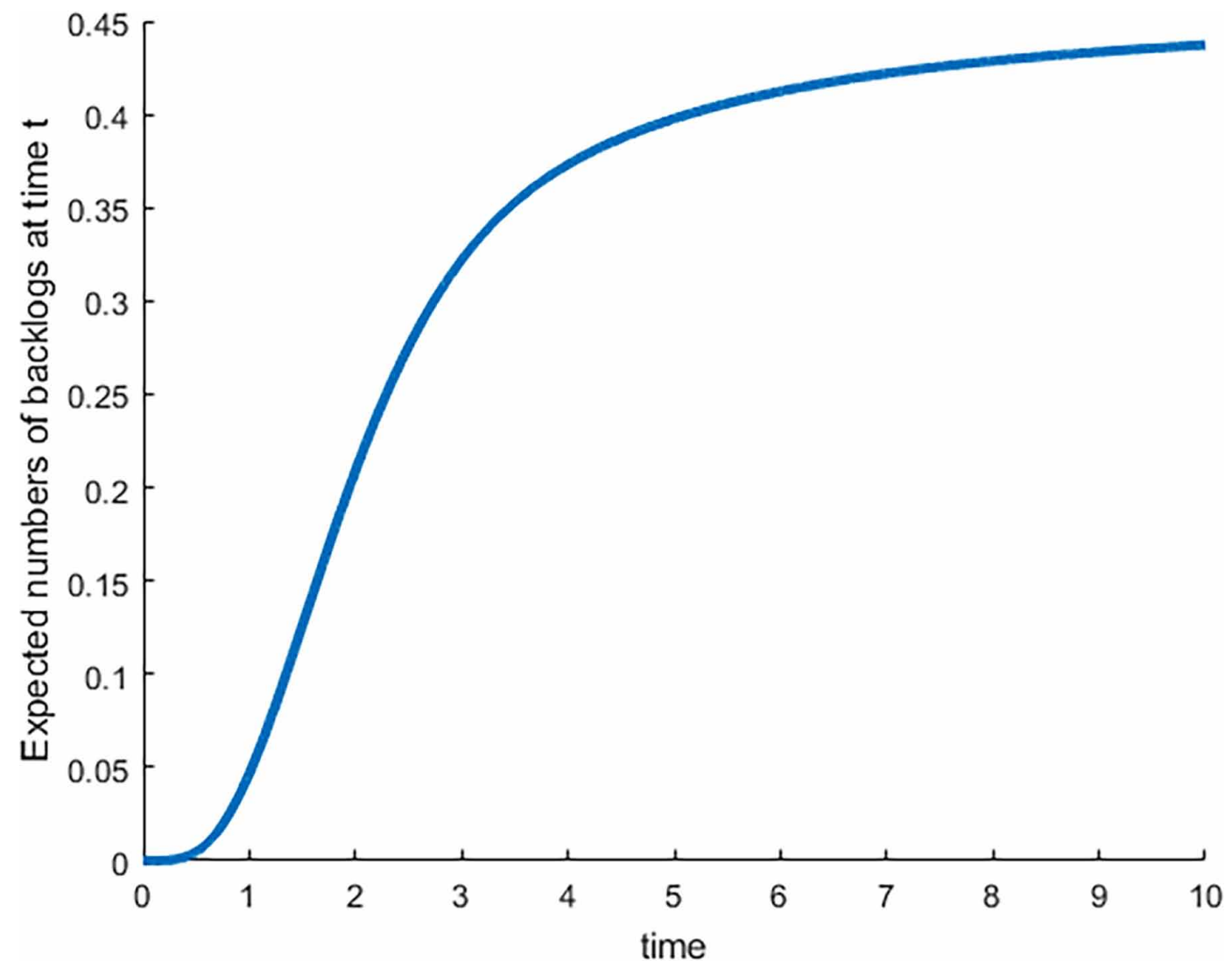


Figure 8. Expected lost sale vs time

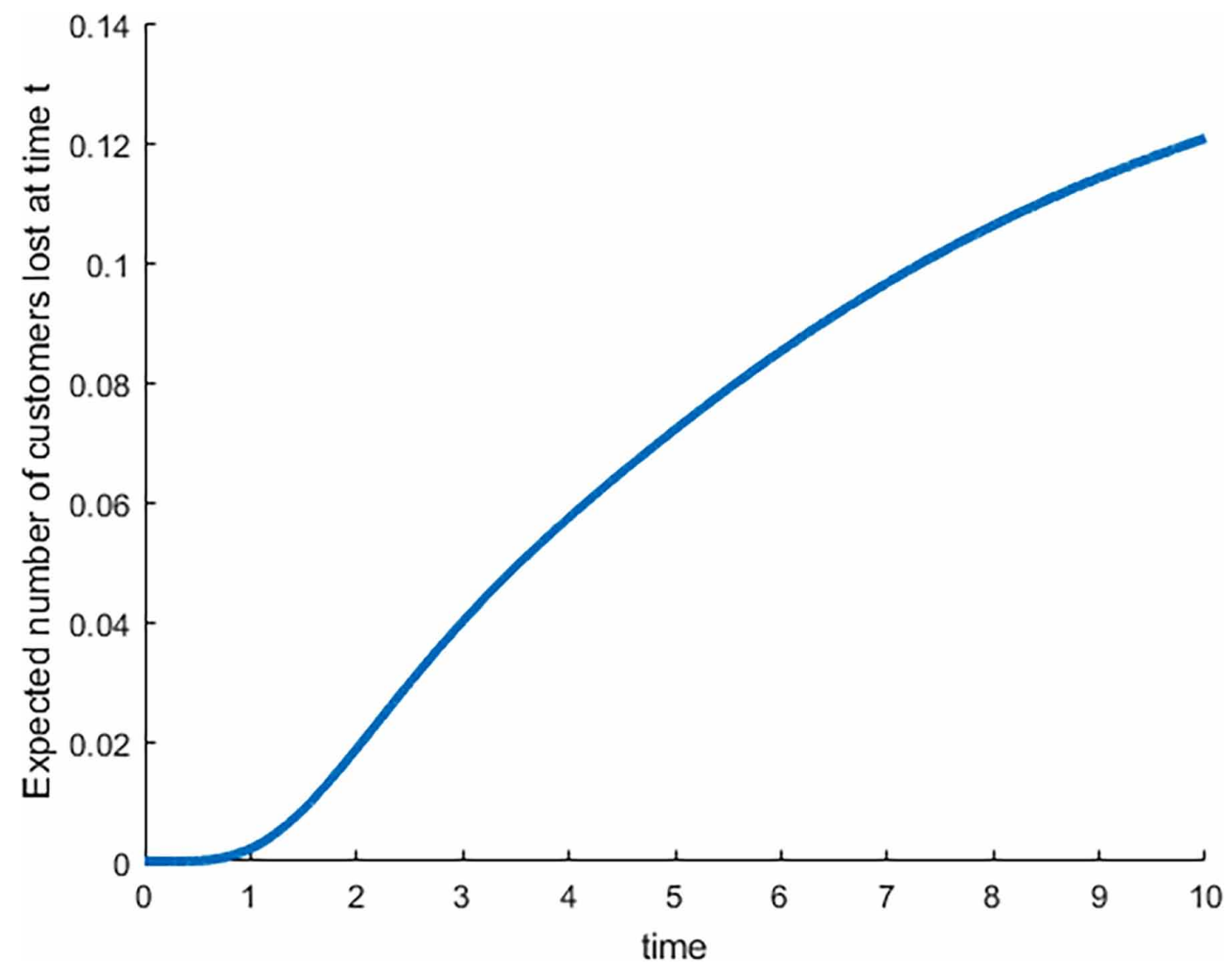


International Journal of Operations Research and Information Systems

Volume 11 • Issue 2 • April-June 2020

Figure 9. Expected Total cost vs time

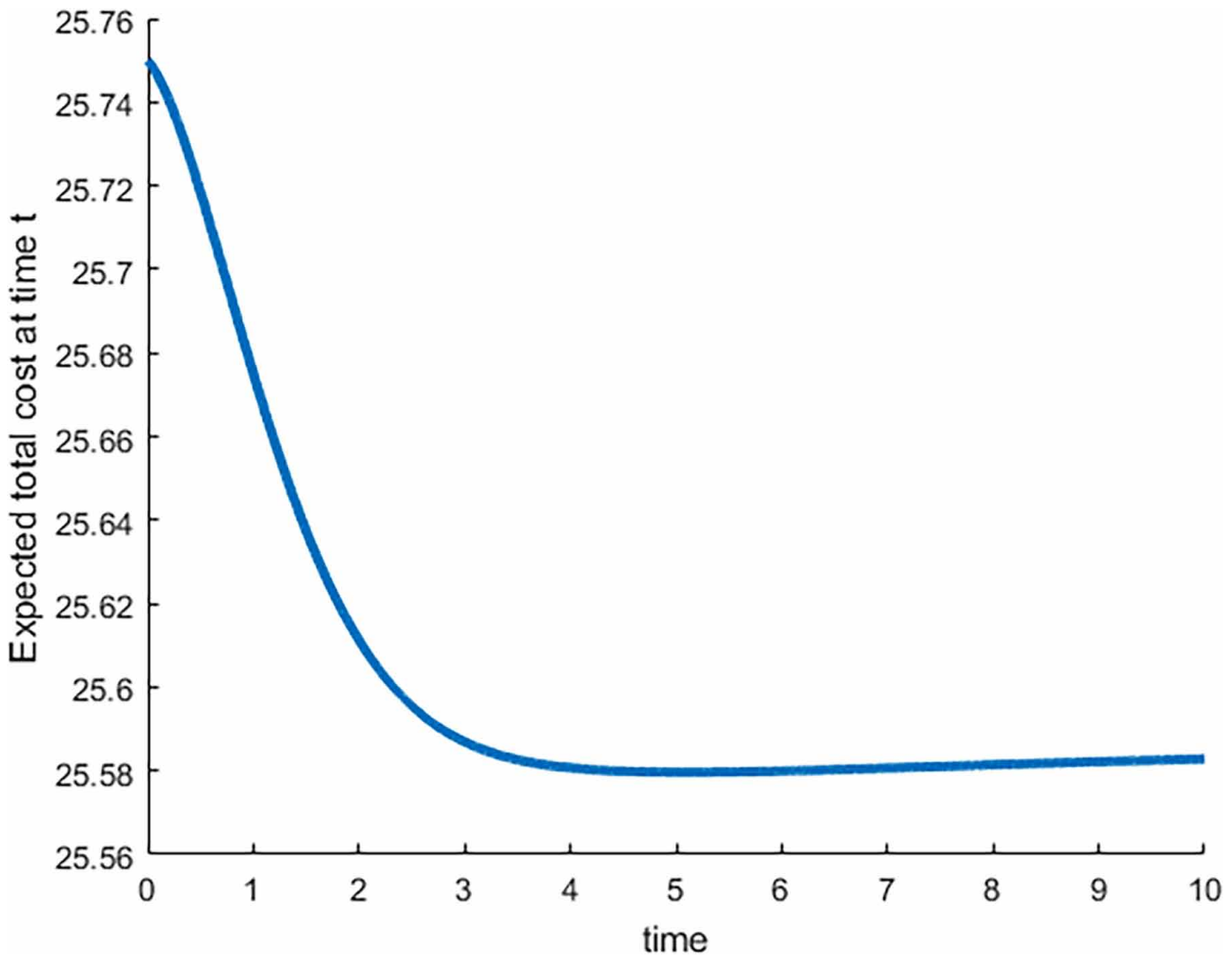




\section{REFERENCES}

Ayyappan, G., \& Shyamala, S. (2013). Time dependent solution of $\mathrm{m}[\mathrm{x}] / \mathrm{g} / 1$ queuing model with bernoulli vacation and balking, International Journal of Computer Applications, 61(21). Retrieved from https://pdfs. semanticscholar.org /8404/7bc1163fe9a2fc03b118e685b07f22844e2c.pdf

Berg, M., Posner, M. J. M., \& Zhao, H. (1994). Production inventory system with unreliable machines. Operations Research, 42(1), 111-118. doi:10.1287/opre.42.1.111

Berman, O., \& Kim, E. (1999). Stochastic models for inventory management at service facilities. Stochastic Models, 15(4), 695-718. doi:10.1080/15326349908807558

Blackburn, J., \& Scudder, G. (2009). Supply Chain Strategies for Perishable Products: The Case of Fresh Produce, Wiley online. The Library, 2009. doi:10.1111/j.1937-5956.2009.01016.x

Chan, R. H., Chunma, K., \& Ching, W. (2006). Boundary value method for solving transient solution of Markovian queuing networks. Applied Mathematics and Computation, 172(2), 690-700. doi:10.1016/j.amc.2004.11.014

Cox, D. R. (1955). A use of complex probabilities in the theory of stochastic processes. Mathematical Proceedings of the Cambridge Philosophical Society, 51(2), 313-319. doi:10.1017/S0305004100030231

Erlenkotter, D. (1990). Ford Whitman Harris and the Economic Order Quantity Model. Operations Research, 38(6), 1990. doi:10.1287/opre.38.6.937

Doshi, B. T. (1986). Queueing systems with vacations-a survey. Queueing Systems, 1(1), 29-66. doi:10.1007/ BF01149327

Federgruen, H. G., \& Tijms, H. C. (1998). Coordinated replenishment in a multi-item inventory system with compound Poisson demands. Management Science, 30(3), 344-357. doi:10.1287/mnsc.30.3.344

Cheng, F. T., Chang, H. H., \& Chiu, S. W. (2010). Economic production quantity model with backordering, rework and machine failure taking place in stock piling time. Wseas Transactions on information science and applications, 7(4), 463-473. Retrieved from https://dl.acm.org/citation.cfm?id=1852521

Ghosh, S. K., Sarkar, T., \& Chudhuri, K. S. (2012). An optimal inventory replenishment policy for a deteriorating item with time-quadratic demand and time dependent partial backlogging with shortages in all cycles, Applied Mathematics and computations, 218, 9147-9155. Retrieved from https://www.sciencedirect.com/science/article/ abs/pii/S0096300312002226

Giri, B. C., \& Dohi, T. (2005). Exact formulation of stochastic EMQ model for an unreliable production system. The Journal of the Operational Research Society, 56(5), 563-575. doi:10.1057/palgrave.jors.2601840

Kalpakam, S., \& Arivarignan, G. (1993). A Coordinated Multi-commodity (s, S) Inventory System, Mathl. Comput. Modelling, 18(11), 69-73. Retrieved from https://ac.els-cdn.com/089571779390206E/1-s2.0089571779390206E-main.pdf?_tid=5abd7a8c-a279-4852-99be-9c04c770fae3\&acdnat=1547275876_11894c 7759b6759bb411d108a6bccadc

Lee, T. (1984). M/G/1/K queue with vacation time and exhaustive service discipline. Operations Research, 32(4), 774-784. doi:10.1287/opre.32.4.774

Mohammad Ekramol Islam, K. M Safiqul Islam, M Sharif Uddin (2013. Inventory system with postponed demands considering reneging pool's and rejecting Buffer's customers. In Proceedings of the International Conference on Mechanical, Industrial and Materials Engineering 2013 (ICMIME2013). Academic Press. Retrieved from http://icmime-ruet.ac.bd/2013/Contents/Technical\%20Papers/Industrial\%20Engineering/IE-01.pdf

Islam, M.E., Miah, M.S., \& Miah, A.B.M.A. (2007). A perishable stochastic inventory models with different rates of production with backlogs and random switching time. Journal of National Academy of Science, 31(2), 231-238. Retried from https://scholar.google.com/citations?user=E5R8MpEAAAAJ\&hl=en

Nahmias, S. (1982). Perishable inventory theory: A review. Operations Research, 30(4), 680-708. doi:10.1287/ opre.30.4.680 PMID:10298625 
Manuel, P., Sivakumar, B., \& Arivarignan, G. (2007). Perishable Inventory System with Postponed Demands and Negative Customers, Journal of Applied Mathematics and Decision. Sciences. Retrieved from https://www. hindawi.com/journals/ads/2007/094850/abs/

Pearn, W. L., \& Chang, Y. C. (2004). Optimal management of N-policy M/Ek/1 queuing system with a removal service station. Journal of Computer and Operation Research, 31, 1001-1055. doi:10.1016/S03050548(03)00048-0

Ramesh Kumar, E., \& Praby Loit, Y. (2016). A Study on Vacation Bulk Queueing Model with setup time and server timeout. IJCMS, 5(12), 81-89. Retrieved from http://academicscience.co.in/ admin/ resources/project/ paper/f201612181482048786.pdf

Li, R., Lan, H., \& Mawhinney, J.R. (2010). A Review on Deteriorating Inventory Study. Journal of Service Science and Management, 3(1), 117-12. Retrieved from http://citeseerx.ist.psu.edu/viewdoc/ summary?doi=10.1.1.612.5230

Selvaraju, N., \& Goswami, C. (2013). Impatient customers in an M/M/1 queue with single and multiple working vacations. Computers \& Industrial Engineering, 65(2), 207-215. Retrieved from https://dl.acm.org/citation. $\mathrm{cfm} ? \mathrm{id}=2480091$

Servi, L. D., \& Finn, S. G. (2002). M/M/1 queues with working vacations (M/M/1/WV). Performance Evaluation, 50(1), 41-52. doi:10.1016/S0166-5316(02)00057-3

Sivakumar, B., \& Arivarignan, G. (2009). A stochastic inventory system with postponed demands. Performance Evaluation, 66(1), 47-58. doi:10.1016/j.peva.2008.08.001

Tian, N. \& Zhang, Z. G. (2006). Vacation Queueing Models: Theory and Applications. Springer. Retrieved from https://www.springer.com/gp/book/9780387337210

Vijaya Laxmi, P., \& Jyothsna, K. (2015). Balking and Reneging Multiple Working Vacations Queue with Heterogeneous Servers. Journal of Mathematical Modelling and Algorithms, 14(3), 267-285. doi:10.1007/ s10852-015-9271-6

Sazvar, Z., Baboli, A., \& Mohammad, R. A. J. (2012). A replenishment policy for perishable products with non-linear bolding cost under stochastic supply lead time. International Journal of Advanced Manufacturing Technology. doi:10.1007/s00170-012-4042-2

Mohammad Ataullah is a PhD student of the Department of Mathematics, Jahangirnagar university, Dhaka, Bangladesh, He is working as an Assistant Professor of Mathematics (Govt. Colleges) in Bangladesh Civil Service. His research interests are the areas of inventory modeling, operations research, mathematical modeling, etc. He has more than ten research articles in these fields.

Mohammad Ekramol (PhD) Islam has completed his PhD in operations Research from Cochin University of Science and Technology, Kerala, India. He is highly involved in research. He has more than fifty publications in the field of stochastic as well as in deterministic inventory models.

Sharif Uddin $(P h D)$ has received his PhD from Japan and working as a Professor of mathematics at Jahangirnagar University, Bangladesh. He is highly involved in research. He has more than seventy-five publications in the field of operations research and inventory models. 